\title{
Comparative Numerical Study on Global Heat Transfer Process in Micro-Channel Gas Coolers with Different Structures
}

\author{
D. Yang, N. Wang, J. Xie ${ }^{\dagger}$ and J. Wang \\ College of Food Science and Technology, Shanghai Ocean University, China \\ Shanghai Professional Technology Service Platform on Cold Chain Equipment Performance and Energy \\ Saving Testing Evaluation, China \\ Shanghai Engineering Research Center of Aquatic Product Processing \& Preservation \\ National Experimental Teaching Demonstration Center for Food Science and Engineering (Shanghai Ocean \\ University), China \\ †Corresponding Author Email: jxie@shou.edu.cn
}

(Received July 9, 2021; accepted October 15, 2021)

\begin{abstract}
A numerical simulation of global heat transfer process in three types of micro-channel heat exchangers was investigated in this paper: spiral double-pipe micro-channel heat exchanger (DPHE), cross-plate micro-channel heat exchanger (CPHE), and shell and tube micro-channel heat exchanger (STHE). The inner tubes of all three heat exchangers have a diameter of $1 \mathrm{~mm}$ and are charged with $\mathrm{CO}_{2}$ as refrigerant. A detailed analysis of the heat exchanger's global heat transfer process was carried out, which is entirely different for different structures. The heat transfer characteristics of supercritical $\mathrm{CO}_{2}$ were analyzed by considering the operating pressure, the refrigerant mass flux, the cooling water mass flux, and the heat exchanger refrigerant inlet temperature. The relationship between the $\mathrm{CO}_{2}$ heat transfer coefficient $\left(h_{\mathrm{CO}_{2}}\right)$ and $\mathrm{CO}_{2}$ bulk temperature $\left(T_{b, \mathrm{CO}_{2}}\right)$ was analyzed in detail. The pseudo-critical temperature $\left(T_{p c}\right)$ mainly determines where the peak $\mathrm{CO}_{2}$ heat transfer coefficient occurs. When $T_{b, \mathrm{CO}_{2}}<T_{p c}$, the rise in $T_{b, \mathrm{CO}_{2}}$ is accompanied by an increase in the heat transfer coefficient, which reaches a maximum when $T_{b, C O_{2}}$ is a little bit higher than the pseudo-critical temperature, the heat transfer coefficient curve begins to decline as $T_{b, \mathrm{CO}_{2}}$ continues to rise. Higher peak heat transfer coefficients can be achieved at higher pressures. Increased refrigerant mass flux always results in larger heat transfer coefficients. The influence of the refrigerant inlet temperature of the heat exchanger in the $T_{b, \mathrm{CO}_{2}}<T_{p c}$ region on the heat transfer coefficient is more significant than expected. In this study, different flow patterns on heat transfer due to different structures were compared. The best heat transfer was achieved using a spiral doublepipe micro-channel heat exchanger (DPHE). It consistently reaches the highest heat transfer and the lowest outlet temperature under the same operating conditions.
\end{abstract}

Keywords: Micro-channel heat exchanger; Supercritical $\mathrm{CO}_{2}$; Heat transfer coefficient.

\section{NOMENCLATURE}

$$
\begin{aligned}
& \text { bulk } \\
& \text { mass flux } \\
& \text { inner wall } \\
& \text { conductivity } \\
& \text { outer wall } \\
& \text { preudo-critical } \\
& \text { heat flux } \\
& \text { temperature } \\
& \text { wall } \\
& \text { axial position } \\
& \text { viscosity }
\end{aligned}
$$

$\begin{array}{ll}C_{P} & \text { specific heat } \\ H & \text { enthalpy } \\ h & \text { heat transfer coefficient } \\ m & \text { mass flow rate } \\ P & \text { pressure } \\ Q & \text { heat exchange } \\ r & \text { reference } \\ u & \text { velocity } \\ x & \text { axial position } \\ z & \text { axial position }\end{array}$




\section{INTRODUCTION}

Trans-critical $\mathrm{CO}_{2}\left(\mathrm{~T}-\mathrm{CO}_{2}\right)$ refrigeration cycle is considered an efficient and environment-friendly system attributed to the complex properties of $\mathrm{CO}_{2}$ near the critical point, widely used in automotive air conditioning, food refrigeration, and heat pumps (Eskandari and Cheraghi 2019). The gas cooler in $\left.\mathrm{T}-\mathrm{CO}_{2}\right)$ refrigeration cycle(Liang et al. 2020; Pan et al. 2020; Rigola et al. 2005; Wang et al. 2018) has to cool $\mathrm{CO}_{2}$ from $373 \mathrm{~K}$ to $298 \mathrm{~K}$ at 8-10 MPa Nekså et al. (1998). The working condition is close to the critical point where the physical properties of $\mathrm{CO}_{2}$ change drastically, which makes it challenging to design gas coolers. Therefore, the micro-channel heat exchanger is the most suitable gas cooler due to its pressure capacity ( Kim and Bullard 2001).

Most of the research on heat exchangers has focused partly on automotive air conditioning $(\mathrm{Li}$ et al. 2017; Wang et al. 2018; Yang et al. 2019) limited by the higher air temperature of secondary flow and partly on printed circuit heat exchangers (Bennett et al. 2020; Katz et al. 2021; Kim et al. 2016; Saeed et al. 2020) limited by the high cost. Han et al. (2012) presented a review of the microchannel heat exchanger development applied in an air-conditioning system. He pointed out the importance of accurately predicting pressure losses and heat transfer characteristics before designing micro-channel heat exchangers. The steep increase and decrease in specific heat and the sudden drop in density cause the heat transfer characteristic of $\mathrm{CO}_{2}$ to be completely different from those substances with constant physical properties. Therefore, a large number of investigations have focused on the heat transfer characteristics of $\mathrm{CO}_{2}$.

Jiang et al. (2008a,b,c) have done extensive research on the supercritical $\mathrm{CO}_{2}$ heat transfer characteristics in vertical tubes. They noted that an increase in heat flux leads to a rise in heat transfer coefficient, but then the upward and downward flowing heat transfer coefficients move in the opposite direction when the heat flux continues to increase. $\mathrm{Xu}$ et al. (2015) experimentally compared the heat transfer in a small serpentine vertical tube and a straight tube. They concluded that the reason why the heat transfer performance of the serpentine tube is better than that of the straight tube is that the secondary flow due to the centrifugal force of the serpentine tube enhanced the heat transfer. Zhang et al. (2019b) conducted a numerical simulation study on the heat transfer characteristics of supercritical $\mathrm{CO}_{2}$ in horizontal semicircular micro-tubes. It was found that specific heat would be in occupying more percentage in influencing the heat transfer process with an absence of buoyancy. Lei et al. (2019) did experiments in order to study the heat transfer characteristics of supercritical $\mathrm{CO}_{2}$ in a small vertical circular tube, especially in the case of low mass flux and high heat flux. He found that the buoyancy force in the small channel plays a decisive role in heat transfer under such conditions.
As mentioned above, several heat transfer studies have been done in single tubes, where the boundary conditions are given a constant wall temperature and constant heat flux. Studies on supercritical $\mathrm{CO}_{2}$ heat transfer mainly focus on the heat transfer characteristics of $\mathrm{CO}_{2}$ in a tube. The boundary conditions are usually a given wall temperature and a constant heat flux. However, it is meaningful to look into water-cooled heat exchangers considering the applications in marine food transportation and heat pumps. The global and local heat transfer coefficients of two types of fluted tube heat exchangers and smooth tube heat exchangers were compared in an experiment by Zhu et al. (2019). The results showed that the global heat transfer coefficient of the smooth tube was only $1 / 3$ of that of the fluted tube.

The most significant heat transfer coefficients were obtained for small hydraulic diameters regardless of the pressure. Wang et al. (2019) conducted experiments on the heat transfer characteristics of supercritical water in a tube-in-tube heat exchanger. The temperature corresponding to the peak heat transfer coefficient is not equal to the pseudo-critical temperature, and the higher the pressure, the more the temperature corresponding to the peak deviates from the pseudo-critical temperature. Cai et al. (2020a) and Ehsan et al. (2018) investigated experimentally and numerically the heat transfer of supercritical $\mathrm{CO}_{2}$ in a micro-tube heat exchanger. He came to the same conclusion as Zhang et al. (2019a) and Wang et al. (2019) and Ma et al. (2016) that buoyancy has a significant effect on heat transfer at low Reynolds number. He also compared extra water flow of shell side process. The best heat transfer effect is achieved by counter-current flow. Most studies on microchannel gas coolers have focused on single-tube heat transfer, simulations of the overall global transfer process of microchannel heat exchangers has rarely been done, while simulation comparison of microchannel air coolers has not been done. For the reason the system we studied is a marine trans-critical $\mathrm{CO}_{2}$ vapor compression cycle refrigeration system with ejectors, it is appropriate to use seawater as the cooling water in the gas cooler. Considering the corrosiveness of seawater and its susceptibility to scaling, shell and tube heat exchangers, doublepipe heat exchangers and cross-plate heat exchangers were preferred because they could be cleaned easily.

In this paper, three different structures of micro-channel gas coolers with an inner diameter of $1 \mathrm{~mm}$ to ensure the same heat transfer area on the $\mathrm{CO}_{2}$ side have been selected according to the existing water-cooled heat exchanger structure on the market. (1) a spiral double-pipe heat exchanger (DPHE). (2) a cross-plate heat exchanger (CPHE). (3) a shell and tube heat exchanger (STHE). The heat transfer characteristics of supercritical $\mathrm{CO}_{2}$ at different pressures, $\mathrm{CO}_{2}$ mass flow rates, water mass flow rates, and $\mathrm{CO}_{2}$ inlet temperatures were investigated numerically to find out the optimal 
structure of the water-cooled micro-channel heat exchanger.

\section{NUMERICAL SIMULATION}

\subsection{Numerical Model}

The structure and dimensions of the three types of micro-channel gas coolers were shown in Fig.1, the distribution of micro-channel in Fig.1a was referred to Guoqing (2015), and Fig.1b was referred to Fronk and Garimella (2011), Fig.1c considered available heat exchanger products on the market. $\mathrm{x}=0 \mathrm{~mm}$ and $\mathrm{x}=10 \mathrm{~mm}$ are the positions of $\mathrm{CO}_{2}$ inlet and outlet in DPHE, respectively, the number of turns is 1 , and the radius of rotation was $15 \mathrm{~mm}$, as shown in Fig. 1. The flow of $\mathrm{CO}_{2}$ and water was counter-current. The CPHE was designed as a seven-plate type with the $\mathrm{CO}_{2}$ inlet at $\mathrm{y}=0$ and the outlet at $\mathrm{y}=-8 \mathrm{~mm}$. The flow of $\mathrm{CO}_{2}$ and water was a cross-flow. $\mathrm{z}=0 \mathrm{~mm}$ and $\mathrm{z}=54 \mathrm{~mm}$ are the positions of $\mathrm{CO}_{2}$ inlet and outlet in STHE respectively.
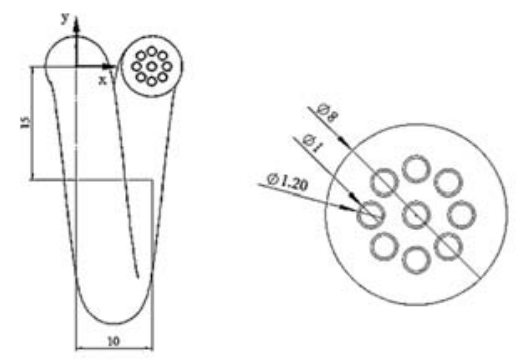

(a) DPHE

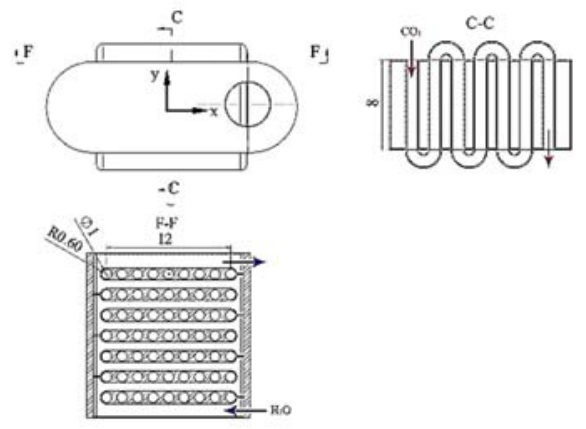

(b) CPHE

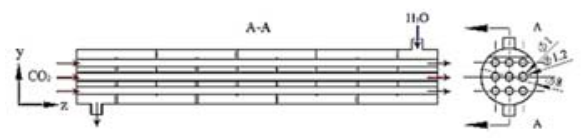

(c) STHE

Fig. 1. Numerical model.

The presence of the baffles ensured that the flow between $\mathrm{CO}_{2}$ and water is counter-flow. The same tube diameter, number of tubes, and tube length are required for all three heat exchangers to ensure the same heat transfer area on the refrigerant side. Supercritical $\mathrm{CO}_{2}$ flowed in 9 circular tubes with a diameter of $1 \mathrm{~mm}$, while water flowed countercurrent or cross-current on the shell side. There was a tube wall of $0.1 \mathrm{~mm}$ thickness between $\mathrm{CO}_{2}$ and water. Following assumptions were required in the simulation:

1. uniform flow on the tube side.

2. uniform flow at the shell side inlet.

3. heat conduction exists only in the vertical direction of the tube wall.

4. ideal counter-flow or cross-flow between $\mathrm{CO}_{2}$ and water.

5. the heat exchangers are placed horizontally.

The global heat transfer processes were simulated using ANSYS fluent 19.0 (Soloveva et al. 2021). SST k- $\omega$ turbulent model (Chen et al. 2018; Wang and Kissick 2020; Yang et al. 2018; Zhang et al. 2020) was selected in this paper. NIST refprop9.11 (Sanaye et al. 2020) was used to reference the properties. Mass-flow inlet and pressure-outlet were chosen as the boundary conditions. Table 1 shows the details of the simulated working conditions.

Table 1 The initial data for the simulations.

\begin{tabular}{|c|c|c|c|c|}
\hline $\begin{array}{c}G_{\mathrm{CO}_{2}} \\
\left(\mathrm{~kg} / \mathrm{m}^{2} \mathrm{~s}\right)\end{array}$ & $\begin{array}{c}G_{\text {water }} \\
\left(\mathrm{kg} / \mathrm{m}^{2} \mathrm{~s}\right)\end{array}$ & $\begin{array}{c}T_{\mathrm{CO}_{2}, \text { in }} \\
(\mathrm{K})\end{array}$ & $\begin{array}{c}P \\
(\mathrm{MPa})\end{array}$ & $\begin{array}{c}T_{\text {water, } \text {, }} \\
(\mathrm{K})\end{array}$ \\
\cline { 1 - 4 } & 100 & 323.15 & 8 & \multirow{2}{*}{288.15} \\
\hline 1000 & 159 & 343.15 & 9 & \multirow{2}{*}{} \\
\hline 1200 & 238 & 373.15 & 10 & \\
\hline
\end{tabular}

\subsection{Governing Equations}

A steady-state method was used in the simulation. The equation for conservation of mass, or continuity equation, can be written as Eq. 1.

$\frac{\partial\left(\rho u_{j}\right)}{\partial x_{j}}=0$

Conservation of momentum is described by Eq. 2 .

$$
\begin{aligned}
\frac{\partial}{\partial x_{j}}\left(\rho u_{i} u_{j}\right) & =\frac{\partial}{\partial x_{j}}\left[\begin{array}{c}
\mu_{e f f}\left(\frac{\partial u_{i}}{\partial x_{j}}+\frac{\partial u_{j}}{\partial x_{i}}\right) \\
-\frac{2}{3} \mu_{e f f} \frac{\partial u_{k}}{\partial x_{k}}
\end{array}\right] \\
& -\frac{\partial p}{\partial x_{j}}+\rho g_{i}
\end{aligned}
$$

where $\mu_{\mathrm{eff}}$ is the effective viscosity which is calculated as Eq. 3 .

$$
\mu_{\text {eff }}=\mu+\mu_{t}
$$

where $\mu_{\mathrm{t}}$ is the turbulent viscosity defined according to the turbulence model.

Conservation of energy is described by Eq. 4 . 


$$
\begin{aligned}
& \frac{\partial\left(\rho u_{i} c_{p} T\right)}{\partial x_{j}}=\frac{\partial}{\partial x_{j}}\left[\begin{array}{c}
\mu_{e f f}\left(\frac{\partial u_{i}}{\partial x_{j}}+\frac{\partial u_{j}}{\partial x_{i}}\right) \\
-\frac{2}{3} \mu_{e f f} \frac{\partial u_{k}}{\partial x_{k}}
\end{array}\right] \\
&+\frac{\partial}{\partial x_{i}}\left(k_{e f f} \frac{\partial T}{\partial x_{i}}\right)
\end{aligned}
$$

where $k_{\text {eff }}$ is the effective conductivity which is calculated as Eq. 5.

$k_{\text {eff }}=k+k_{t}$

where $k_{t}$ is the turbulent thermal conductivity defined according to the turbulence model.

$\mathrm{k}$ - equation and $\omega$ - equation are described by Eq. 6 and Eq. 7.

$$
\begin{aligned}
& \frac{\partial\left(\rho u_{j} k\right)}{\partial x_{j}}=\frac{\partial}{\partial x_{j}}\left(\mu+\frac{\mu_{t}}{\sigma_{k}}\right) \frac{\partial k}{\partial x_{j}}+P_{k}-D_{k}+S_{k} \\
& \frac{\partial\left(\rho u_{j} \omega\right)}{\partial x_{j}}=\frac{\partial}{\partial x_{j}}\left(\mu+\frac{\mu_{t}}{\sigma_{\omega}}\right) \frac{\partial \omega}{\partial x_{j}}+C_{\omega}+P_{\omega}-D_{\omega}
\end{aligned}
$$

\subsection{Data Reduction}

After the simulation is completed, the results of the inner and outer wall temperature and heat flux along the axial line can be output directly in STHE and CPHE. The bulk temperature of $\mathrm{CO}_{2}$, the water temperature, and the heat transfer coefficient need to be calculated twice. All the above variables in DPHE are subject to a secondary calculation. The $\mathrm{CO}_{2}$ heat transfer coefficient inside was calculated by

$$
h_{\mathrm{CO}_{2}}=\frac{q_{w, i n}}{T_{b, \mathrm{CO}_{2}}-T_{w, i n}}
$$

where $q_{w, \text { in }}$ and $T_{w, \text { in }}$ were the average wall heat flux and the internal wall temperature along the axial line, respectively, which were calculated by

$$
\begin{aligned}
& q_{w, \text { in }}=\frac{\int q d L}{L} \\
& T_{w, \text { in }}=\frac{\int T d L}{L}
\end{aligned}
$$

$\mathrm{L}$ was the heat exchange pipe's length, the axial position in STHE is equal to $\mathrm{z}$ and $\mathrm{y}$ in CPHE. $\mathrm{L}$ in DPHE represents the direction along the helix. The $\mathrm{CO}_{2}$ bulk temperature was calculated by

$$
T_{b, C O_{2}}=\frac{\int \rho u c_{p} T d A}{\int \rho u c_{p} d A}
$$

The water heat transfer coefficient was calculated by

$h_{\mathrm{H}_{2} \mathrm{O}}=\frac{q_{w, \text { out }}}{T_{w, \text { out }-} T_{b, \mathrm{H}_{2} \mathrm{O}}}$

where $q_{w, \text { out }}$ and $T_{w, \text { out }}$ were the average wall heat flux and the outer wall temperature along the axial line, respectively. The water temperature was calculated by

$$
T_{b, H_{2} O}=\frac{\int \rho u c_{p} T d A}{\int \rho u c_{p} d A}
$$

The total heat exchange was calculated as follows

$Q_{\text {exchange }}=m_{\mathrm{CO}_{2}}\left(\mathrm{H}_{\mathrm{CO}_{2}, \text { in }}-\mathrm{H}_{\mathrm{CO}_{2}, \text { out }}\right)$

\subsection{Reliability Verification}

\subsubsection{Model Validation}

Since experiments on supercritical $\mathrm{CO}_{2}$ double-pipe heat exchangers have been done previously, this paper directly used the previously obtained experimental data to verify the validity of the simulation. The specific equipment of the experiments and the working conditions can be found in Ref. Yang et al. (2017). Figure 2 showed a comparison of the numerical and experimental results for different pressures. The SST k- $\omega$ turbulent model is proved to be accurate and reliable in the heat transfer prediction.

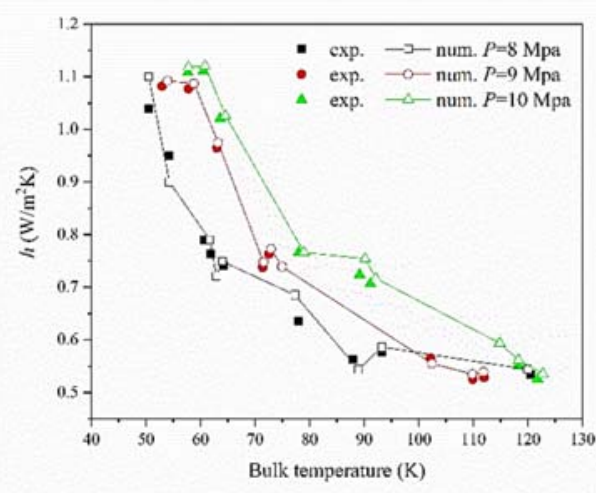

Fig. 2. Comparison of numerical calculation results with experimental results.

\subsubsection{Grid Independence}

Table 2. shows the pressure drop for different grid numbers. It can be seen that the pressure drop in the cross-plate heat exchanger is no longer significant for a grid partition of 2917110 , and 3382495 for the shell and tube heat exchanger, 2245768 for the double-pipe heat exchanger. Therefore, grids with the numbers 2917110, 3382495, and 2245768 were selected to save computational time.

\section{RESULTS AND DISCUSSIONS}

\subsection{Global Heat Transfer Processes}

Figure $3 \mathrm{ab}$ shows the global heat transfer process in CPHE, including axial temperature, axial wall heat flux, and axial local $\mathrm{CO}_{2}$ heat transfer coefficient. Only the first plate of the flow channel is intercepted 
D. Yang et al. / JAFM, Vol. 15, No. 2, pp. 579-589, 2022.

for analysis because the global analysis of the crossplate flow along the axial direction is complicated.

Table 2 Mesh independence verification.

\begin{tabular}{|c|c|c|c|}
\hline cases & $\begin{array}{c}\text { Number } \\
\text { of meshes }\end{array}$ & $\begin{array}{c}\text { Pressure } \\
\text { drop }\end{array}$ & Error(\%) \\
\hline CPHE & 1089997 & 1935.8 & 48.2 \\
\cline { 2 - 4 } & 1577912 & 1483 & 13.5 \\
\cline { 2 - 4 } & 2205040 & 1381 & 5.7 \\
\cline { 2 - 4 } & 2917110 & 1325.8 & 1.5 \\
\cline { 2 - 4 } & 3892329 & 1306.2 & 0 \\
\hline STHE & 1032040 & 429.8 & 2.94 \\
\cline { 2 - 4 } & 1995913 & 426.2 & 2.09 \\
\cline { 2 - 4 } & 2579068 & 424.1 & 1.3 \\
\cline { 2 - 4 } & 3382495 & 433 & 0.49 \\
\cline { 2 - 4 } & 4213105 & 436.6 & 0 \\
\hline DPHE & 839664 & 631.3 & 48.8 \\
\cline { 2 - 4 } & 1682660 & 466.6 & 10.0 \\
\cline { 2 - 4 } & 2245768 & 430.1 & 1.4 \\
\cline { 2 - 4 } & 3368652 & 424 & 0 \\
\hline
\end{tabular}

The heat exchange process can be roughly divided into three parts in CPHE, based on the heat flux along the axial line in Fig. 3a: $\mathrm{CO}_{2}$ inlet section, relatively stable section, and water inlet section. The high heat flux at the $\mathrm{CO}_{2}$ inlet is attributed to the vast temperature difference between the refrigerant and cooling water and the higher $\mathrm{CO}_{2}$ heat transfer coefficient caused by the inlet effect in Fig.3b. As the $\mathrm{CO}_{2}$ heat transfer coefficient drops rapidly, it causes the heat flux to fall into the stabilization process. The rapid increase in the heat transfer coefficient of $\mathrm{CO}_{2}$ is attributed to the bulk temperature of $\mathrm{CO}_{2}$ approaching the critical point during the cooling process, where the physical properties of $\mathrm{CO}_{2}$ change dramatically and the specific heat dominates the heat transfer process, causing the heat transfer coefficient to have the same trend as the specific heat. As mentioned before, the specific heat increases in the $T_{b}<T_{p c}$ and decreases in the region of $T_{b}>T_{p c}$. Although the $\mathrm{CO}_{2}$ heat transfer coefficient and the total heat transfer coefficient increase, the temperature difference keeps dropping, so the heat flux also tends to decrease slightly. As the $\mathrm{CO}_{2}$ temperature decreases, the $\mathrm{CO}_{2}$ undergoes a phase change from a supercritical to a subcritical state, causing the heat flux to drop further until there is a slight rebound at the water inlet. That may be due to the high heat transfer coefficient of water at the water inlet. The heat transfer coefficient of water is found to be as much as five times higher than that of $\mathrm{CO}_{2}$ at the $\mathrm{CO}_{2}$ outlet by calculation. The heat transfer process in DPHE is similar to the above.

Figure 3cd shows the heat transfer process in STHE, including axial temperature, axial heat flux, and axial $\mathrm{CO}_{2}$ heat transfer coefficient. The global heat transfer process in STHE is clearly distinguished from the heat transfer process in CPHE. First of all, the heat flux changes more drastically than that in CPHE, which is more attributed to the difference in the structure. The baffles in STHE changes the direction of water flow in the shell side. The presence of the baffles in STHE makes the heat flux change

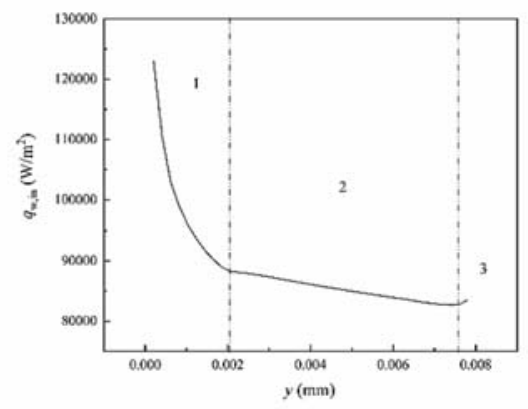

(a) Heat flux of the CPHE inner wall

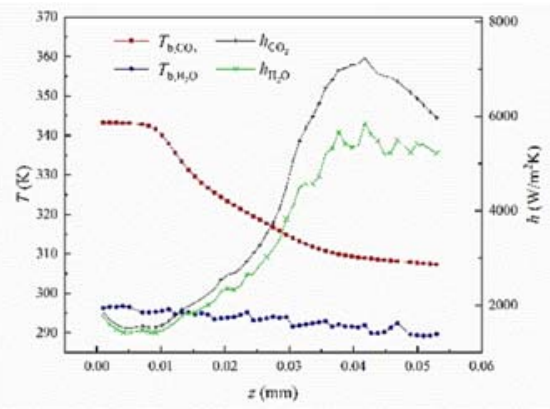

(b) Temperature distribution along the CPHE tube

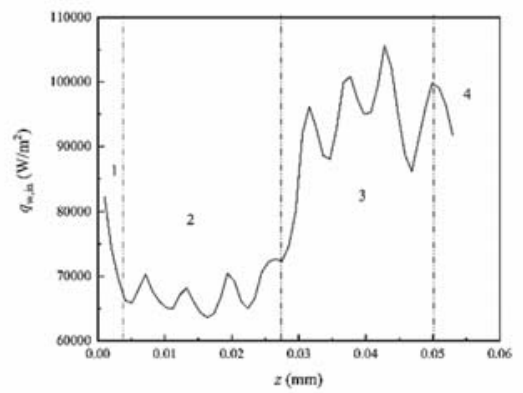

(c) Heat flux of the STHE inner wall

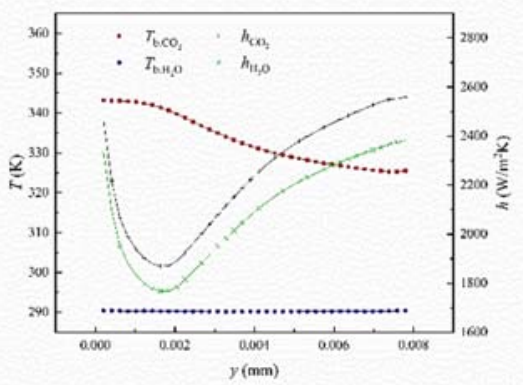

(d) Temperature distribution along the STHE tube

Fig. 3. Global heat transfer process in CPHE and

$$
\begin{gathered}
\text { STHE. }\left(G_{c o_{2}, \text { in }}=100 \mathrm{~kg} / \mathbf{m}^{2} \mathbf{s},\right. \\
G_{\text {water }}=1000 \mathrm{~kg} / \mathrm{m}^{2} \mathbf{s}, T_{\text {water }, \text { in }}=288.15 \mathrm{~K}, \\
\left.\boldsymbol{T}_{\boldsymbol{c o _ { 2 } , \text { in }}}=343.15 \mathrm{~K}, \mathbf{P}=\mathbf{M P a}\right)
\end{gathered}
$$

more drastically along the axial direction. Still, the whole process can be roughly divided into four parts: $\mathrm{CO}_{2}$ inlet section, lower section, higher section, and 
water inlet section, as shown in Fig. 3c. Similarly, the high heat flux at the inlet is caused by the vast temperature difference between the refrigerant and cooling water, as shown in Fig. 3d. As the $\mathrm{CO}_{2}$ heat transfer coefficient drops and rises, as shown in Fig. $3 \mathrm{~d}$, the temperature difference between the refrigerant and cooling water barely changes, causing the heat flux to decrease into the lower section. As the $\mathrm{CO}_{2}$ temperature decreases, the $\mathrm{CO}_{2}$ heat transfer coefficient increases dramatically again into the higher section attributed to the falling slowly temperature difference between the refrigerant and cooling water for the same reason the dramatically changing specific heat of $\mathrm{CO}_{2}$. The temperature difference does not continue to decrease, and the $\mathrm{CO}_{2}$ heat transfer coefficient and heat flux both reach their peak until the water inlet. It is obvious that the heat transfer process is entirely different for different structures of heat exchangers. Therefore, it is vital to analyze the global heat exchanger heat transfer process in order to design an efficient and compact heat exchanger. Baffles should be considered in the design of microchannel heat exchangers by comparing the heat transfer processes of CPHE and STHE. In addition, the global analysis of the heat exchanger shows that the heat transfer coefficient of $\mathrm{CO}_{2}$ and water keeps changing all the time, which is noteworthy. The heat transfer characteristics of supercritical $\mathrm{CO}_{2}$ in a heat exchanger are worth studying in order to design an efficient and compact heat exchanger.

\section{2 s- $\mathrm{CO}_{2}$ Heat Transfer Characteristics}

\subsubsection{Effects of Pressure}

The operating pressure range of the heat exchanger in a trans-critical $\mathrm{CO}_{2}$ refrigeration cycle is mostly 8 $10 \mathrm{MPa}$. This pressure range was investigated in this study. The trend of heat transfer coefficient at different pressures is shown in Fig. 4. It is clear that when $T_{b, C O_{2}}<T_{p c}$, the rise in $T_{b, C O_{2}}$ is accompanied by an increase in the heat transfer coefficient, which reaches a maximum when $\mathrm{T}_{b, \mathrm{CO}_{2}}$

is a little bit higher than the pseudo-critical temperature, the heat transfer coefficient curve begins to decline as $T_{b, \mathrm{CO}_{2}}$ continues to rise. Higher peak heat transfer coefficients can be achieved at higher pressures.

This is consistent with the trend in specific heat, and it is easy to see that this is attributed to a dramatic change in specific heat. No significant difference in the peak of $\mathrm{CO}_{2}$ heat transfer coefficients at different pressures for the three heat exchangers. A new reference temperature was defined to estimate the temperature at which the peak heat transfer coefficient of $\mathrm{CO}_{2}$ occurs (Cai et al. 2020b), which was calculated by

$T_{r, \mathrm{CO}_{2}}=0.8 \times T_{b}+0.2 \times T_{w}$

This equation is used to estimate the location of the peak $\mathrm{CO}_{2}$ heat transfer coefficient occurrence before the post-processing, and the simulation results are consistent with the estimated value.

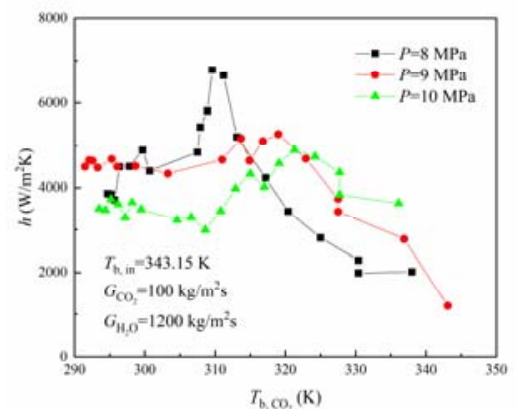

(a) DPHE

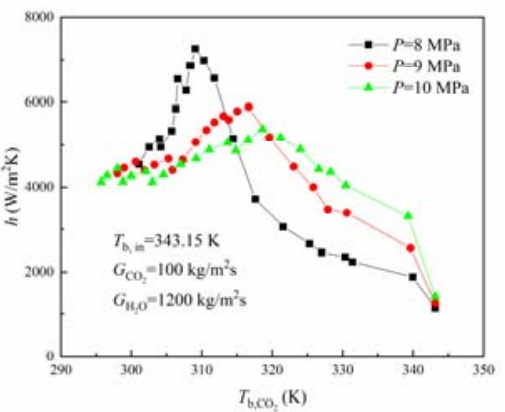

(b) CPHE

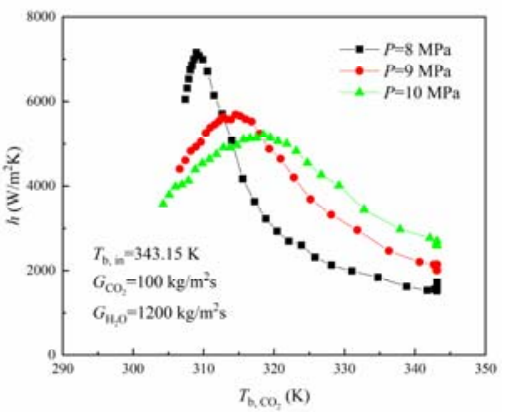

(c) STHE

Fig. 4. The $h_{\mathrm{CO}_{2}}$ at different pressure.

$$
\begin{gathered}
\left(G_{c_{2}, \text { in }}=100 \mathbf{k g} / \mathbf{m}^{2} \mathbf{s}, G_{\text {water }}=1200 \mathrm{~kg} / \mathbf{m}^{2} \mathbf{s}\right. \\
\left.\boldsymbol{T}_{\text {water }, \text { in }}=288.15 \mathrm{~K}, \boldsymbol{T}_{\text {co }_{2}, \text { in }}=343.15 \mathrm{~K},\right)
\end{gathered}
$$

\subsubsection{Effects of $\mathrm{CO}_{2}$ Mass Flux}

Different $\mathrm{CO}_{2}$ mass fluxes on the heat transfer coefficient cannot be underestimated. Figure 5 shows the trend of the $\mathrm{CO}_{2}$ heat transfer coefficient at different $\mathrm{CO}_{2}$ mass fluxes. It was found that increased refrigerant mass flux always results in larger heat transfer coefficients. The peak of the heat transfer coefficient also occurs at temperatures slightly above the critical temperature. Obviously, a higher heat transfer coefficient and lower $\mathrm{CO}_{2}$ outlet temperature in DPHE can be obtained at the same $\mathrm{CO}_{2}$ inlet temperature and operating pressure. The peak $\mathrm{CO}_{2}$ heat transfer coefficients of all three heat exchangers occur at similar temperatures, indicating that this is entirely dominated by the $\mathrm{CO}_{2}$ heat transfer characteristics and is not related to the heat exchanger structure. 


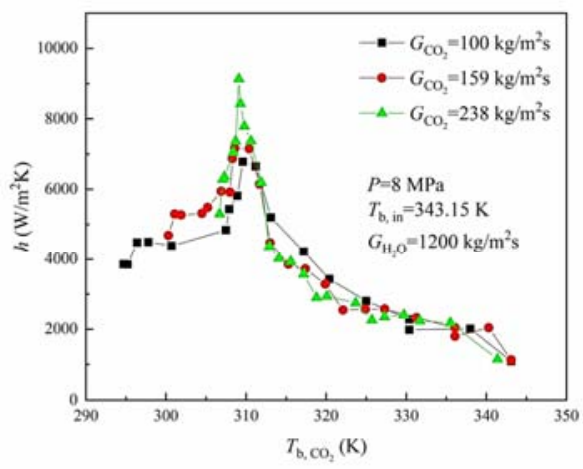

(a) DPHE

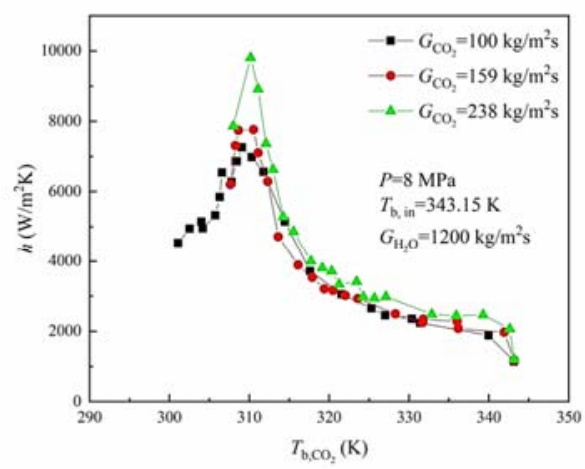

(b) CPHE

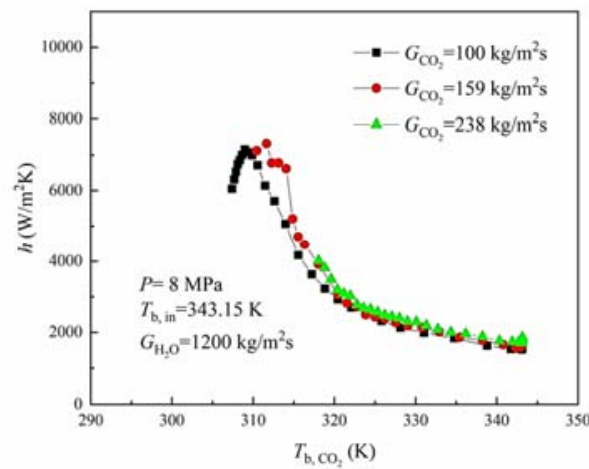

(c) STHE

Fig. 5. The $h_{\mathrm{CO}_{2}}$ at different $\mathrm{G}_{\mathrm{CO}_{2}}$.

\subsubsection{Effects of Water Mass Flux}

The trend of heat transfer coefficient at different water mass fluxes is shown in Fig. 6. It is expected that at high Reynolds numbers, the mass flux of water hardly affects the heat transfer process. Slightly in the $T_{b}<T_{p c}$ region, the reason why high water mass fluxes have high heat transfer coefficients are attributed to the vast temperature difference at the inlet. As the global heat transfer process proceeds, the temperature difference between the refrigerant and cooling water falling slowly, the $\mathrm{CO}_{2}$ heat transfer coefficient almost does not change.

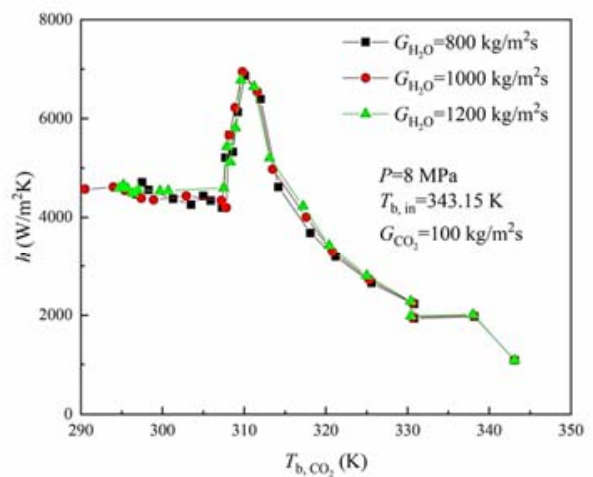

(a) DPHE

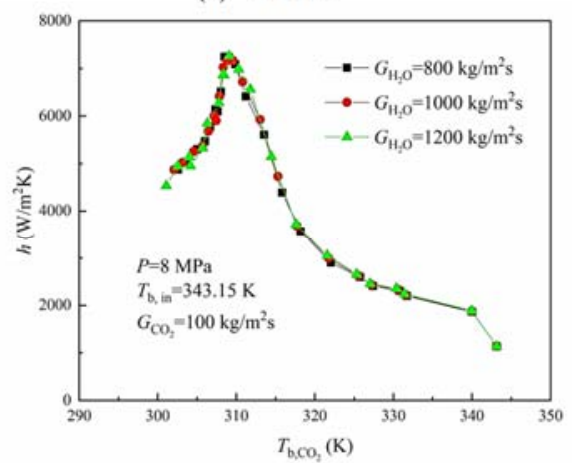

(b) CPHE

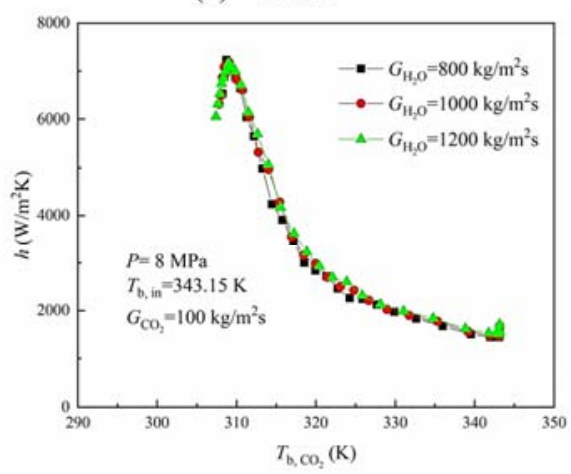

(c) STHE

Fig. 6. The $h_{\mathrm{CO}_{2}}$ at different $G_{\mathrm{H}_{2} \mathrm{O}}$.

\subsubsection{Effects of Gas Cooler Inlet Temperature}

The trend of heat transfer coefficient at different heat exchanger inlet temperatures is shown in Fig. 7. The heat transfer coefficient first drops significantly, then increases to the first peak in the $T_{b}<T_{p c}$ region and reaches the second peak at a slightly higher than the pseudo-critical temperature, as can be shown in Fig. $7 \mathrm{a}$ and Fig. 7b. Both DPHE and CPHE show heat transfer coefficient fluctuations that occur in the subcritical region, while STHE does not show the situation described above due to its poor cooling effect and higher gas cooler outlet temperature than DPHE and CPHE, as can be seen in Fig. 7c. 


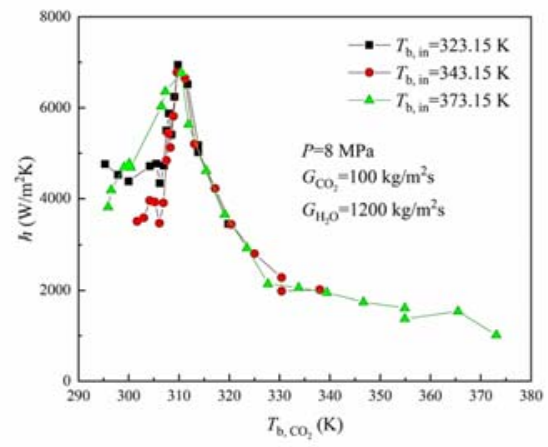

(a) DPHE

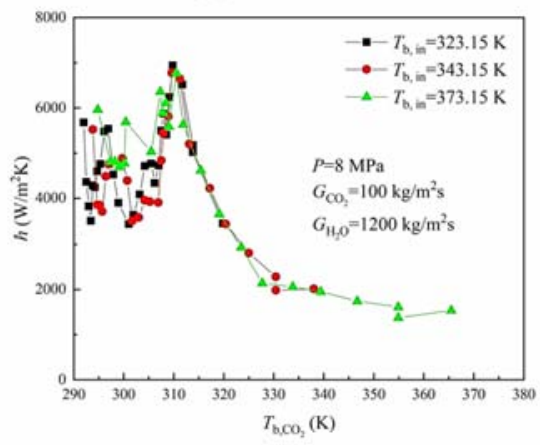

(b) $\mathrm{CPHE}$

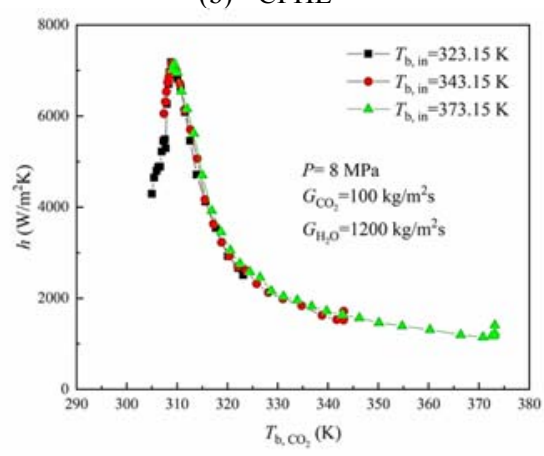

(c) STHE

Fig. 7. The $h_{\mathrm{CO}_{2}}$ at different $T_{b, \text { in }}$.

\subsection{Effects of structure}

The comparison of the supercritical $\mathrm{CO}_{2}$ heat transfer characteristics of the three types of gas coolers in section 3.2 is equivalent to comparing the heat transfer characteristics of supercritical $\mathrm{CO}_{2}$ in the horizontal spiral micro-tube, a horizontal serpentine micro-tube, and a horizontal straight micro-tube, where it is clear that the different flow patterns lead to different heat transfer effects. Similarly, the study of the complicated flow on the waterside is also essential for the design of micro-channel gas coolers due to the inhomogeneity of $\mathrm{CO}_{2}$ properties derived from section 3.2. In this paper, the heat transfer effects of three heat exchangers were compared, and the results are shown in Table 3.

It can be found that the DPHE heat exchange effect is better than CPHE and STHE with the same heat transfer area on the $\mathrm{CO}_{2}$ side. In fact, Guo et al. (2019) found that the cooling conditions spiral tube heat transfer effect is better than the straight tube, similarly Zheng et al. (2019) found that the serpentine tube heat transfer effect is better than the straight tube; the conclusion reached in this paper is that the heat transfer effect spiral tube is the strongest, followed by the serpentine tube, the worst is the straight tube. Figure 8 shows the temperature distribution at the outlet cross-section for each of the three different flow types at different operating conditions. The supercritical $\mathrm{CO}_{2}$ near the inner wall is cooled first. It is found that DPHE always obtains the lowest outlet temperature for the same operating conditions. The structure of spiral double-pipe counter-current flow can effectively cool $\mathrm{CO}_{2}$.

\section{Conclusion}

In this study, the heat transfer process between $\mathrm{CO} 2$ and water in three different structures of micro-channel heat exchangers was investigated in detail, and numerical simulations were performed to compare and analyze the three heat exchangers.

The heat transfer processes of the three heat exchangers were analyzed in detail.

Table 1 The $Q_{\text {exchange }}$ of three heat exchangers.

\begin{tabular}{|c|c|c|c|c|c|c|c|c|c|c|c|c|}
\hline \multirow{2}{*}{$\begin{array}{c}\mathrm{Q} \\
\mathrm{W})\end{array}$} & \multicolumn{2}{|c|}{$G_{\mathrm{Co}_{2}}\left(\mathrm{~kg} / \mathrm{m}^{2} \mathrm{~s}\right)$} & \multicolumn{3}{c|}{$G_{\text {water }}\left(\mathrm{kg} / \mathrm{m}^{2} \mathrm{~s}\right)$} & \multicolumn{3}{c|}{$T_{b, \text { in }}(\mathrm{K})$} & \multicolumn{3}{c|}{$P(\mathrm{MPa})$} \\
\cline { 2 - 13 } & 100 & 159 & 238 & 800 & 1000 & 1200 & 323.15 & 343.15 & 373.15 & 8 & 9 & 10 \\
\hline STHE & 13.2 & 13.5 & 13.5 & 11.8 & 12.4 & 13.2 & 12.4 & 15.2 & 18.3 & 13.2 & 14.3 & 14.4 \\
\hline CPHE & 17.4 & 19.1 & 20.0 & 16.7 & 16.6 & 17.4 & 13.2 & 17.4 & 18.2 & 17.4 & 16.6 & 16.0 \\
\hline DPHE & 18.2 & 29.5 & 36.4 & 19.7 & 21.0 & 18.2 & 14.4 & 19.8 & 24.6 & 18.2 & 18.0 & 15.8 \\
\hline
\end{tabular}




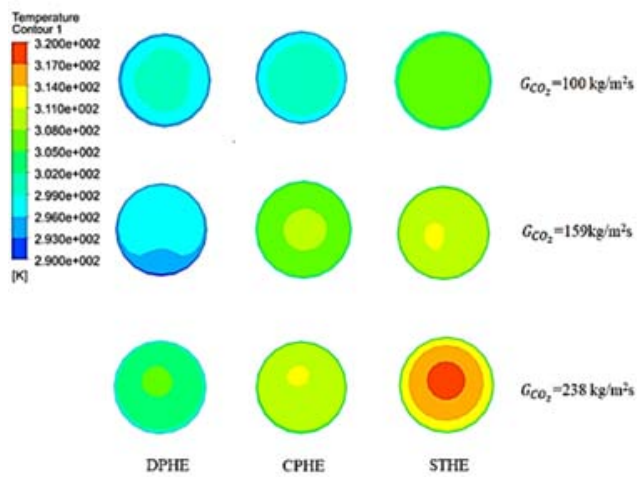

(a) Temperature variation at different $G_{\mathrm{CO}_{2}}$

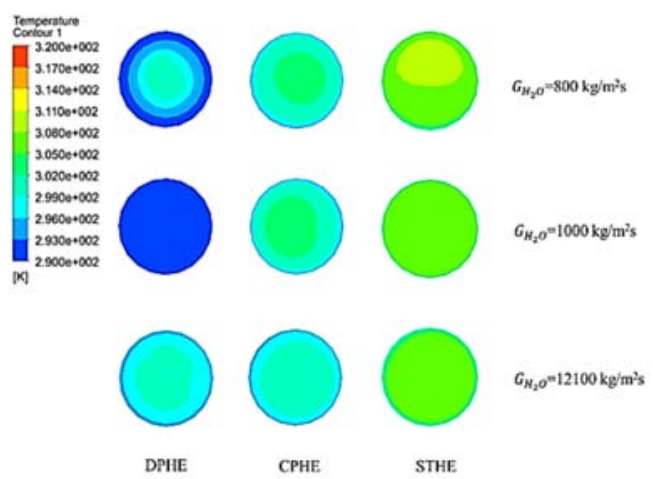

(b) Temperature variation at different $G_{\mathrm{H}_{2} \mathrm{O}}$

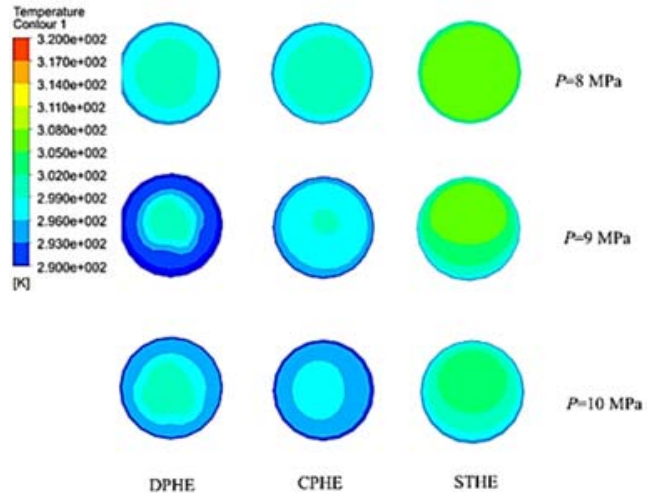

(c) Temperature variation at different $P$

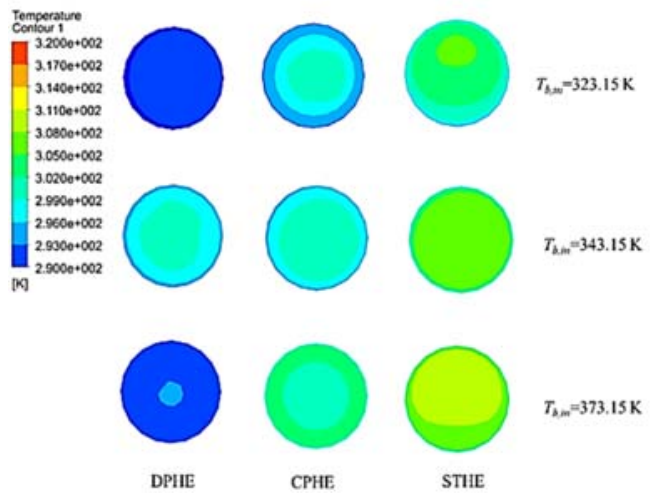

(d) Temperature variation at different $T_{b, i n}$

Fig. 8. Temperature distribution at the outlet.
The effects of $\mathrm{CO}_{2}$ pressure, the mass flux of $\mathrm{CO}_{2}$, the mass flux of water, heat exchanger inlet temperature, and different flow patterns between $\mathrm{CO}_{2}$ and water on the heat transfer effectiveness of the heat exchanger were considered. The following conclusions were drawn from this study.

1. The heat transfer process is entirely different for different structures of heat exchangers. Baffles should be considered in the design of microchannel heat exchangers. The heat transfer coefficient of $\mathrm{CO}_{2}$ and water keeps changing all the time.

2. Increased refrigerant mass flux always results in more significant heat transfer coefficients. The peak of the heat transfer coefficient also occurs at temperatures slightly above the critical temperature, while the mass flux of water hardly affects the heat transfer process at high mass flux.

3. The heat transfer coefficient in CTHE first decreases significantly in the subcritical region thermal coefficient, then rises to the first peak in the region where the $\mathrm{CO}_{2}$ bulk temperature is below the pseudo-critical temperature and reaches the second peak at the pseudo-critical temperature with different inlet temperatures, which is not present in DPHE and STHE.

4. DPHE has the best heat transfer effect, followed by CTHE, and the worst STHE and DPHE always obtains the lowest outlet temperature for the same operating conditions.

\section{ACKNOWLEDGEMENTS}

This paper is supported by this research has been supported by Science and technology innovation action plan of Shanghai Science and Technology Commission ((19DZ1207503).

\section{REFERENCES}

Bennett, K. and Y. Chen. (2020). One-way coupled three-dimensional fluid-structure interaction analysis of zigzag-channel supercritical $\mathrm{CO} 2$ printed circuit heat exchangers. Nuclear Engineering and Design 358, 110434.

Cai, H. fei, Y. yan Jiang, T. Wang, S. qiang Liang and Y. ming Zhu. (2020a). Experimental investigation on convective heat transfer and pressure drop of supercritical $\mathrm{CO} 2$ and water in microtube heat exchangers. International Journal of Heat and Mass Transfer 163, 120443.

Cai, H. fei, S. qiang Liang, C. hong Guo, T. Wang, Y. ming Zhu and Y. yan Jiang. (2020b). Numerical investigation on heat transfer of supercritical carbon dioxide in the microtube heat exchanger at low reynolds numbers. International Journal of Heat and Mass Transfer 151, 119448.

Chen, W., Z. Yang, L. Yang and M. K. Chyu. (2018). Numerical investigation of heat transfer and flow characteristics of supercritical $\mathrm{CO}_{2}$ in $\mathrm{U}$ - 
D. Yang et al. / JAFM, Vol. 15, No. 2, pp. 579-589, 2022.

duct. Applied Thermal Engineering 144, $532-$ 539.

Ehsan, M. M., Z. Guan and A. Y. Klimenko. (2018). A comprehensive review on heat transfer and pressure drop characteristics and correlations with supercritical $\mathrm{CO} 2$ under heating and cooling applications. In Renewable and Sustainable Energy Reviews 92, 658-675.

Eskandari Manjili, F. and M. Cheraghi. (2019). Performance of a new two-stage transcritical $\mathrm{CO} 2$ refrigeration cycle with two ejectors. Applied Thermal Engineering 156, 402-409.

Fronk, B. M. and S. Garimella. (2011). Watercoupled carbon dioxide microchannel gas cooler for heat pump water heaters: Part II Model development and validation. International Journal of Refrigeration 34(1), $17-28$.

Guo, J., M. Xiang, H. Zhang, X. Huai, K. Cheng and X. Cui. (2019). Thermal-hydraulic characteristics of supercritical pressure $\mathrm{CO} 2$ in vertical tubes under cooling and heating conditions. Energy 170, 1067-1081.

Guoqing, S. (2015). Study on fluid flow and heat transfer in a mini channel tube-in-tube heat exchanger. In Chinese.

Han, Y., Y. Liu, M. Li and J. Huang. (2012). A review of development of micro-channel heat exchanger applied in air-conditioning system. Energy Procedia 14, 148-153.

Jiang, P. X., Y. Zhang and R. F. Shi. (2008). Experimental and numerical investigation of convection heat transfer of $\mathrm{CO} 2$ at supercritical pressures in a vertical mini-tube. International Journal of Heat and Mass Transfer 51(11-12), 3052-3056.

Jiang, P. X., Y. Zhang, Y. J. Xu and R. F. Shi. (2008). Experimental and numerical investigation of convection heat transfer of $\mathrm{CO} 2$ at supercritical pressures in a vertical tube at low Reynolds numbers. International Journal of Thermal Sciences 47(8), 998-1011.

Jiang, P. X., Y. Zhang, C. R. Zhao and R. F. Shi. (2008). Convection heat transfer of $\mathrm{CO} 2$ at supercritical pressures in a vertical mini tube at relatively low reynolds numbers. Experimental Thermal and Fluid Science 32(8), 1628-1637.

Katz, A., S. R. Aakre, M. H. Anderson and D. Ranjan. (2021). Experimental investigation of pressure drop and heat transfer in high temperature supercritical $\mathrm{CO} 2$ and helium in a printed-circuit heat exchanger. International Journal of Heat and Mass Transfer 171, 121089.

Kim, M. H. and C. W. Bullard. (2001). Development of a microchannel evaporator model for a $\mathrm{CO} 2$ air-conditioning system. Energy 26(10), 931948.
Kim, S. G., Y. Lee, Y. Ahn and J. I. Lee. (2016). CFD aided approach to design printed circuit heat exchangers for supercritical CO2 Brayton cycle application. Annals of Nuclear Energy 92, 175-185.

Lei, X., J. Zhang, L. Gou, Q. Zhang and H. Li. (2019). Experimental study on convection heat transfer of supercritical $\mathrm{CO} 2$ in small upward channels. Energy 176, 119-130.

Li, J., J. Jia, L. Huang and S. Wang. (2017). Experimental and numerical study of an integrated fin and micro-channel gas cooler for a $\mathrm{CO} 2$ automotive air-conditioning. Applied Thermal Engineering 116, 636-647.

Liang, Y., Z. Sun, M. Dong, J. Lu and Z. Yu. (2020). Investigation of a refrigeration system based on combined supercritical $\mathrm{CO} 2$ power and transcritical $\mathrm{CO} 2$ refrigeration cycles by waste heat recovery of engine. International Journal of Refrigeration 118, 470-482.

Ma, T., W. X. Chu, X. Y. Xu, Y. T. Chen and Q. W. Wang. (2016). An experimental study on heat transfer between supercritical carbon dioxide and water near the pseudo-critical temperature in a double pipe heat exchanger. International Journal of Heat and Mass Transfer 93, 379387.

Nekså, P., H. Rekstad, G. R. Zakeri and P. A. Schiefloe. (1998). CO2-heat pump water heater: Characteristics, system design and experimental results. International Journal of Refrigeration 21(3), 172-179.

Pan, M., X. Bian, Y. Zhu, Y. Liang, F. Lu and G. Xiao. (2020). Thermodynamic analysis of a combined supercritical $\mathrm{CO} 2$ and ejector expansion refrigeration cycle for engine waste heat recovery. Energy Conversion and Management 224, 113373.

Rigola, J., G. Raush, C. D. Pérez-Segarra and A. Oliva. (2005). Numerical simulation and experimental validation of vapour compression refrigeration systems. Special emphasis on $\mathrm{CO} 2$ trans-critical cycles. International Journal of Refrigeration 28(8), $1225-1237$.

Saeed, M., A. S. Berrouk, M. Salman Siddiqui and A. Ali Awais. (2020). Numerical investigation of thermal and hydraulic characteristics of sCO2-water printed circuit heat exchangers with zigzag channels. Energy Conversion and Management 224(August), 113375.

Sanaye, S., N. Khakpaay, A. Chitsaz, M. Hassan Yahyanejad and M. Zolfaghari. (2020). A comprehensive approach for designing, modeling and optimizing of waste heat recovery cycle and power generation system in a cement plant: A thermo-economic and environmental assessment. Energy Conversion and Management, 205(September 2019), 112353. 
D. Yang et al. / JAFM, Vol. 15, No. 2, pp. 579-589, 2022.

Soloveva, O., S. Solovev and R. Yafizov. (2021). Hydrodynamics and Convective Heat Transfer in Open Cell Foam with Micropores. Transportation Research Procedia 54, 64-68.

Wang, D., B. Yu, W. Li, J. Shi and J. Chen. (2018). Heating performance evaluation of a $\mathrm{CO} 2$ heat pump system for an electrical vehicle at cold ambient temperatures. Applied Thermal Engineering 142(July), 656-664.

Wang, H. and S. M. Kissick. (2020). Modeling and simulation of a supercritical CO2-liquid sodium compact heat exchanger for sodiumcooled fast reactors. Applied Thermal Engineering 180, 115859.

Wang, Q., Z. Song, Y. Zheng, Y. Yin, L. Liu, H. Wang and J. Yao. (2019). Coupled convection heat transfer of water in a double pipe heat exchanger at supercritical pressures: An experimental research. Applied Thermal Engineering 159, 113962.

$\mathrm{Xu}$, R. N., F. Luo and P. X. Jiang. (2015). Experimental research on the turbulent convection heat transfer of supercritical pressure $\mathrm{CO} 2$ in a serpentine vertical mini tube. International Journal of Heat and Mass Transfer 91, 552-561.

Yang, D., J. Xie, J. Lv and J. Wang. (2017). An Experimental and Numerical Study of Helix Tube Gas Cooler for Super-Critical Carbon Dioxide. Journal of Chemical Engineering of Japan 50(12), 900-908.

Yang, J., B. Yu and J. Chen. (2019). Improved genetic algorithm-based prediction of a $\mathrm{CO} 2$ micro-channel gas-cooler against experimental data in automobile air conditioning system. International Journal of Refrigeration 106, 517-525.

Yang, Z., W. Chen and M. K. Chyu. (2018). Numerical study on the heat transfer enhancement of supercritical $\mathrm{CO} 2$ in vertical ribbed tubes. Applied Thermal Engineering $145,705-715$.

Zhang, S., X. Xu, C. Liu, X. Liu, Z. Ru and C. Dang. (2020). Experimental and numerical comparison of the heat transfer behaviors and buoyancy effects of supercritical $\mathrm{CO} 2$ in various heating tubes. International Journal of Heat and Mass Transfer 149.

Zhang, Y., M. Peng, G. Xia and T. Cong. (2019a). Numerical investigation on local heat transfer characteristics of $\mathrm{S}-\mathrm{CO} 2$ in horizontal semicircular microtube. Applied Thermal Engineering 154, 380-392.

Zheng, Y., P. X. Jiang, F. Luo and R. N. Xu. (2019b). Instability during transition to turbulence of supercritical pressure $\mathrm{CO} 2$ in a vertical heated serpentine tube. International Journal of Thermal Sciences 145(September 2018), 105976.

Zhu, Y., Y. Huang, S. Lin, C. Li and P. Jiang. (2019). Study of convection heat transfer of $\mathrm{CO} 2$ at supercritical pressures during cooling in fluted tube-in-tube heat exchangers. International Journal of Refrigeration 104, 161-170. 